\title{
ACOMPANHAMENTO QUÍMICO DA VERMICOMPOSTAGEM DE LODO DE ESGOTO DOMÉSTICO
}

\author{
Paulo R. Dores-Silva, Maria D. Landgraf e Maria Olímpia O. Rezende* \\ Instituto de Química de São Carlos, Universidade de São Paulo, CP 780, 13560-970 São Carlos - SP, Brasil
}

Recebido em 28/7/10; aceito em 12/1/11; publicado na web em 1/4/11

\begin{abstract}
CHEMICAL MONITORING OF VERMICOMPOSTING FROM DOMESTIC SEWAGE SLUDGE. This research aims to monitor the humification process of domestic sewage sludge resulted from the vermicomposting, evaluating, also, the possibility of using the final product (vermicompost) in agricultural soils. The monitored chemical variables during the 90 days of vermicomposting were: humidity rate, organic matter content, nitrogen and phosphorus content, pathogenic organisms concentration, total organic carbon, acidity, $\mathrm{CEC}, \mathrm{C} / \mathrm{N}$ ratio, $\mathrm{CEC} / \mathrm{TOC}$ ratio, and humic and fulvic acids content. The change in these variables during the vermicomposting process showed that this technique is effective for use in the maturation of the residue.
\end{abstract}

Keywords: domestic sewage sludge; Eisenia fetida; vermicomposting.

\section{INTRODUÇÃO}

O lodo de esgoto doméstico (LED) é um resíduo rico em matéria orgânica, além de ser uma fonte de micro e macronutrientes para solos agricultáveis, o que confere a esses solos, quando se utiliza LED como condicionador ou fertilizante, uma maior capacidade de retenção de água, maior resistência à erosão e, ao mesmo tempo, oferece uma resolução razoável e ambientalmente adequada para o destino final do resíduo gerado durante o tratamento das águas residuárias nas Estações de Tratamento de Esgoto (ETE).

\section{Necessidade da estabilização do lodo de esgoto doméstico}

A necessidade de estabilização do LED está ligada principalmente a duas características negativas: seu potencial para produzir odores e ao seu alto conteúdo de micro-organismos patogênicos. ${ }^{1}$ Os odores gerados em uma ETE são devidos, principalmente, a compostos contendo enxofre. Sulfetos podem ser produzidos pela redução biológica de sulfatos e de outros compostos orgânicos contendo S.

Com a finalidade de diminuir ou até mesmo eliminar os inconvenientes do odor e da presença de patógenos no resíduo, são empregados vários processos, dentre eles processos químicos e biológicos que, utilizando vários mecanismos, estabilizam o lodo. Após ser estabilizado, o LED recebe o nome de biossólido. ${ }^{2}$

No processo de estabilização biológica, são utilizados os mecanismos naturais de biodegradação que transformam os compostos de maior grau de biodegradabilidade presentes no lodo. Os metabolismos envolvidos podem ser anaeróbios ou aeróbios. ${ }^{1}$

Além dos processos biológicos para estabilização do LED existe o processo químico de transformação, que consiste da adição de produtos químicos que podem inibir a atividade biológica ou oxidar a matéria orgânica. $\mathrm{O}$ tratamento químico mais utilizado é a via alcalina, em que uma base, normalmente a cal, é misturada ao lodo, elevando seu $\mathrm{pH}$ e inativando a maior parte dos micro-organismos patogênicos presentes. Além da cal, são utilizados em menor escala outros tipos de produtos químicos, tais como, cloro, ozônio, peróxido de hidrogênio e permanganato de potássio. ${ }^{3}$

\footnotetext{
*e-mail: mrezende@iqsc.usp.br
}

\section{Disposição final do lodo de esgoto}

No Brasil, a disposição final do LED, geralmente, é o aterro sanitário. Além do alto custo, que pode chegar a mais de $50 \%$ do custo operacional de uma ETE, a disposição de um resíduo com elevada carga orgânica no aterro agrava o problema com o manejo dos resíduos sólidos urbanos. ${ }^{4}$

Neste contexto, a reciclagem agrícola se destaca pela sua adequação sanitária e ambiental. O uso agrícola do LED como fertilizante orgânico é considerado hoje uma alternativa promissora de disposição final desse resíduo. ${ }^{5,6}$

A adição de biossólidos alcalinizados em solos pode levar à modificação das características químicas desses solos, elevando o pH a níveis superiores a 7,5; neste patamar, a dinâmica de nutrientes e a atividade biológica dos solos são drasticamente alteradas prejudicando a absorção de nutrientes, o desenvolvimento e a produtividades das culturas. Os biossólidos alcalinizados contêm, ainda, grande

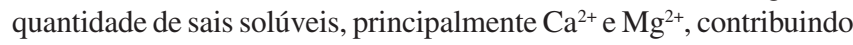
para elevação da pressão osmótica do solo, podendo causar danos aos vegetais e até sua morte. ${ }^{7}$

Visando sanar esses problemas, propõe-se a utilização do LED como matriz para a produção de vermicomposto popularmente conhecido como húmus de minhoca, fertilizante conhecido por seu alto teor de matéria orgânica estabilizada.

\section{O processo de vermicompostagem}

A vermicompostagem é o processo de transformação de matéria orgânica recente, isto é, pouco degradada, por meio da ação das minhocas junto com a flora que vive em seu trato digestivo, em matéria orgânica estabilizada..$^{8-11}$

O principal processo envolvido na ação das minhocas sobre a matéria orgânica é mais mecânico que biológico: o revolvimento e a aeração do composto, bem como a trituração das partículas orgânicas que passam pelo trato digestivo desses animais constituem um processo puramente mecânico. A contribuição do efeito bioquímico está presente quando da decomposição da matéria orgânica pelos microorganismos existentes no intestino das minhocas, gerando resíduos mais ricos em nutrientes assimiláveis pelas plantas. ${ }^{12-15}$ 


\section{Utilização da técnica de vermicompostagem na estabilização do lodo de esgoto doméstico}

Existem diferentes formas para a disposição final do lodo, tais como aterros sanitários, incineração, deposição em oceanos ou em água doce e como adubo e/ou condicionador de solos na agricultura. ${ }^{16}$ Estas opções apresentam algumas desvantagens: a incineração é cara e pode poluir a atmosfera, a deposição em oceanos ou em cursos de água doce aumenta o teor de matéria orgânica, acarretando uma possível eutrofização do manancial, diminuindo a quantidade de oxigênio dissolvido. ${ }^{17}$

A disposição final do LED não está resolvida. A principal preocupação deve ser a de encontrar uma forma de descartar esse lodo, que seja ambientalmente adequada e que agregue valor ao resíduo gerado pelas ETE.

O presente trabalho teve por objetivo acompanhar o processo de humificação promovido pela vermicompostagem durante 90 dias de experimento, avaliando, também, a possibilidade do produto final (vermicomposto) ser incorporado em solos agrícolas, apresentando-se, assim, como uma ferramenta útil e sustentável para disposição final do LED. As variáveis químicas monitoradas durante o processo de vermicompostagem foram: teor de umidade, teor de matéria orgânica, carbono orgânico total, quantidade de nitrogênio Kjeldahl total, $\mathrm{P}$ total, determinação de ovos viáveis de helmintos, acidez, capacidade de troca catiônica, razão $\mathrm{C} / \mathrm{N}$ e razão capacidade de troca catiônica/carbono orgânico total.

\section{PARTE EXPERIMENTAL}

\section{Preparação dos vermicompostos}

Para a realização do experimento foram montadas três caixas construídas com madeira compensada, não herméticas, de $0,70 \mathrm{~m}$ de comprimento, 0,70 m de largura e 0,70 m de altura, onde em cada uma foram adicionados $60 \mathrm{~L}$ de uma mistura de LED (com $40 \%$ de umidade) e solo nas seguintes proporções: $100 \%$ de LED (A), $75 \%$ de LED e $25 \%$ de solo (B) (v/v) e $50 \%$ de LED e $50 \%$ de solo (C) (v/v). A inoculação foi realizada com minhocas Eisenia fetida, as caixas foram mantidas em local parcialmente aberto e uma cobertura vegetal foi adicionada na superfície do material quando este já havia sido disposto nas caixas, com o intuito de proteger as minhocas da luz.

A vermicompostagem foi realizada no município de São Carlos e o LED utilizado foi cedido gratuitamente pela estação de tratamento de esgotos de Água Vermelha, município de São Carlos, e mantido com cerca de $40 \%$ de umidade. O solo utilizado foi um latossolo vermelho-amarelo, cuja caracterização química está apresentada no item Resultados e Discussão.

Antes de serem transferidos para as caixas, o lodo e as respectivas misturas (A, B, e C) foram adequadamente homogeneizados em pilhas com auxílio de enxada. Só então o material foi transferido para as caixas, retirando-se de cada uma, 3 alíquotas em locais distintos e aleatórios e, por fim, foram inoculadas 400 minhocas da espécie Eisenia fetida a cada uma das caixas. ${ }^{18}$

Após a inoculação, as minhocas realizaram o processo de compostagem do material durante 90 dias, sendo tal processo acompanhado experimentalmente pela medida da temperatura e por amostragens quinzenais perfazendo um total de 7 coletas para determinações das variáveis. A primeira coleta foi efetuada no dia zero, e assim, sucessivamente, a saber: $2^{\mathrm{a}}(\operatorname{dia} 15), 3^{\mathrm{a}}(\operatorname{dia} 30), 4^{\mathrm{a}}(\operatorname{dia} 45), 5^{\mathrm{a}}(\operatorname{dia}$ $60), 6^{\mathrm{a}}($ dia 75$)$ e $7^{\mathrm{a}}$ (dia 90).

\section{Metodologia}

Foi realizada a caracterização química dos vermicompostos, segundo as seguintes variáveis: $\mathrm{pH}$ em $\mathrm{CaCl}_{2}$; nitrogênio Kjedahl total (NKT), ${ }^{19}$ Hach método 399; fósforo, Hach método 480; carbono orgânico (COT) via TOC-V COH Shimadzu; capacidade de troca catiônica (CTC), através de ocupação dos sítios ativos de troca com íons de hidrogênio em solução $1 \mathrm{~mol} \mathrm{~L}^{-1}$ de ácido acético glacial; teor de matéria orgânica (MO) e umidade (U), via gravimetria e, para a determinação da concentração de ovos viáveis de helmintos, utilizou-se o método de Yanko. ${ }^{20}$

\section{Extração e quantificação dos ácidos húmicos e fúlvicos}

A extração e quantificação dos ácidos húmicos $(\mathrm{AH})$ e ácidos fúlvicos $(\mathrm{AF})$ foram realizadas de acordo com a metodologia convencional sugerida pela Sociedade Internacional de Substâncias Húmicas (IHSS). ${ }^{21}$

\section{Tratamento estatístico dos resultados e tratamento dos resíduos gerados}

Com exceção da análise de ovos viáveis de helmintos, todas as demais determinações foram executadas em quintuplicata, determinando-se a média aritmética e, posteriormente, o desvio padrão amostral. Foi realizado também o tratamento estatístico de Student, para um nível de confiança de $95 \%$ e o erro da medida foi calculado pela Equação 1:

$$
\mathrm{e}= \pm(\mathrm{tx} \sigma) / \mathrm{V}_{\mathrm{n}}
$$

sendo, e = erro da medida; $\mathrm{t}=$ coeficiente de Student tabelado para um limite de confiança de $95 \% ; \sigma=$ desvio-padrão; $\mathrm{n}=$ número de repetições.

As determinações de COT, NKT, concentração de ovos viáveis de helmintos e CTC foram realizadas em amostras secas a $65^{\circ} \mathrm{C}$.

Os resíduos gerados foram encaminhados ao Laboratório de Resíduos Químicos para descarte adequado. ${ }^{22}$

\section{RESULTADOS E DISCUSSÃO}

\section{Teor de umidade}

Os resultados para o teor de umidade estão apresentados na Tabela 1.

Tabela 1. Variação da umidade (\% em massa) ao longo do processo de vermicompostagem

\begin{tabular}{ccccccccc}
\hline Coletas & $\mathrm{A}$ & $\mathrm{e}$ & $\mathrm{B}$ & $\mathrm{e}$ & $\mathrm{C}$ & $\mathrm{e}$ & Solo & $\mathrm{e}$ \\
\hline $1^{\mathrm{a}}$ & 38,32 & 0,52 & 33,10 & 0,84 & 26,13 & 0,79 & 16,96 & 0,10 \\
$2^{\mathrm{a}}$ & 40,56 & 1,22 & 34,78 & 2,18 & 31,09 & 2,57 & & \\
$3^{\text {a }}$ & 40,61 & 1,61 & 32,74 & 1,50 & 27,80 & 0,90 & & \\
$4^{\text {a }}$ & 42,94 & 0,48 & 35,74 & 0,79 & 28,82 & 0,51 & & \\
$5^{\text {a }}$ & 37,66 & 0,88 & 32,28 & 0,64 & 28,10 & 0,46 & & \\
$6^{\text {a }}$ & 36,75 & 0,37 & 30,39 & 0,10 & 24,08 & 0,47 & & \\
$7^{\text {a }}$ & 38,55 & 0,26 & 32,19 & 0,39 & 25,22 & 0,62 & & \\
\hline
\end{tabular}

$\mathrm{A}=$ Vermicomposto com matriz de $100 \%$ lodo de esgoto doméstico; $\mathrm{B}=$ Vermicomposto com matriz $75 \%$ lodo de esgoto doméstico e $25 \%$ solo; $\mathrm{C}=$ Vermicomposto com matriz $50 \%$ lodo de esgoto doméstico e $50 \%$ solo; $\mathrm{e}=$ erro da medida para $\mathrm{n}=5$, onde $\mathrm{n}=$ número de amostras

Analisando a Tabela 1 nota-se que houve variações no teor de umidade ao longo da vermicompostagem. Isso se deve ao fato de que as caixas não estavam em um local fechado. Logo, ocorreram variações aleatórias no teor de umidade no decorrer da vermicompostagem. 
Teor de matéria orgânica e acidez das amostras ao longo do processo de vermicompostagem

Na Figura 1 está representada a variação no teor de matéria orgânica e a variação no valor de $\mathrm{pH}$ nos três testes $(\mathrm{A}, \mathrm{B}$ e C) durante os 90 dias de vermicompostagem.
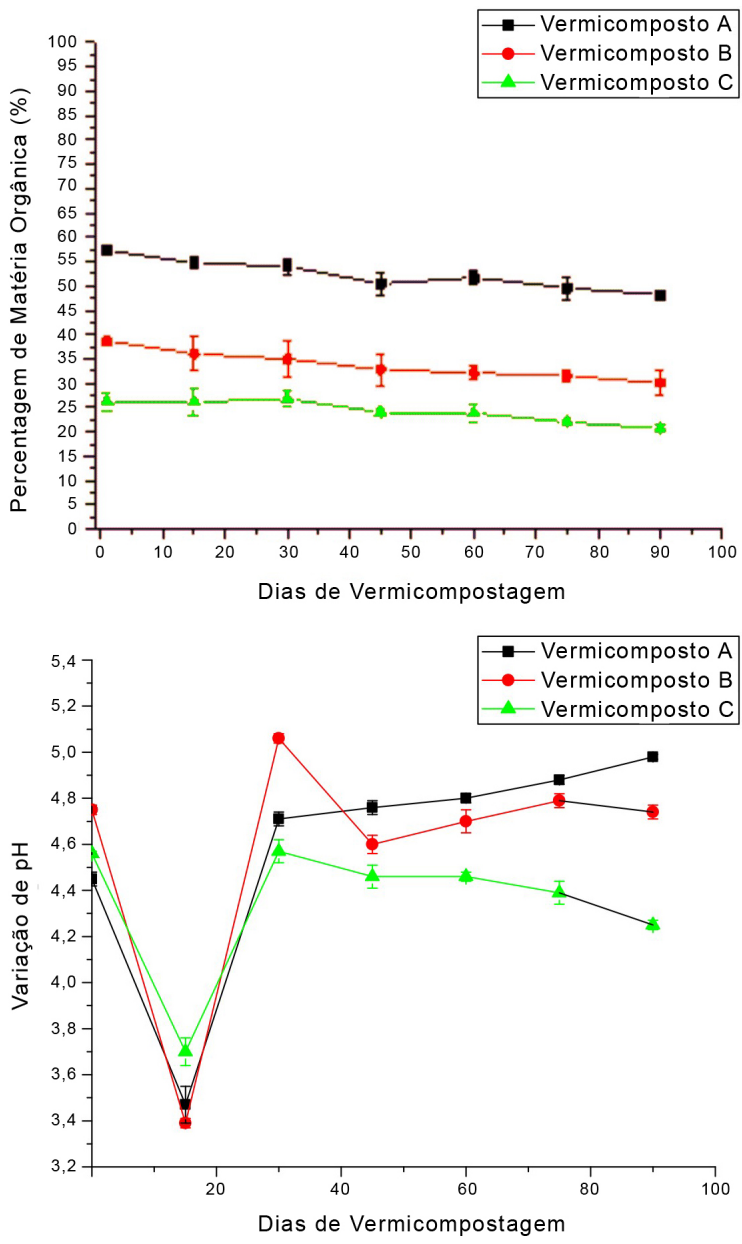

Figura 1. ( $\left.a_{1}\right)$ Variação no teor de matéria orgânica e $\left(a_{2}\right)$ variação no $p H$, durante os 90 dias de vermicompostagem

Houve uma gradativa diminuição no teor de matéria orgânica nos vermicompostos A, B e C. Isso ocorre devido ao metabolismo das minhocas, que utilizam parte da matéria orgânica existente no vermicomposto para seu desenvolvimento, evidenciando, também, que o processo de vermicompostagem está em andamento e que, desta maneira, está ocorrendo a mineralização do carbono orgânico para $\mathrm{CO}_{2}$.

Pode ser observado que na $2^{\mathrm{a}}$ coleta ( 15 dias) houve uma diminuição brusca no $\mathrm{pH}$ para todas as matrizes. Já para as coletas posteriores, percebe-se um aumento gradativo no $\mathrm{pH}$ do vermicomposto $\mathrm{A}$. O vermicomposto $\mathrm{B}$ não apresentou essa tendência, sendo o $\mathrm{pH}$ final praticamente igual ao $\mathrm{pH}$ do primeiro dia de vermicompostagem; por fim, o $\mathrm{pH}$ do vermicomposto representado por $\mathrm{C}$ apresentou uma ligeira tendência de decréscimo durante os 90 dias de teste.

Observou-se que as minhocas se adaptaram bem aos vermicompostos testados durante os primeiros 30 dias de vermicompostagem. Após esse período, percebeu-se que elas apresentaram uma tendência a se atrofiar, tendência esta observada com maior intensidade na caixa A (100\% LED). Esse fato pode ter ocorrido devido à alteração no valor do $\mathrm{pH}$ nos primeiros 15 dias, o que pode ter causado um processo de toxicidade crônica nas minhocas, que se manifestou 30 dias após o início da vermicompostagem. Em estudos simultâneos, comprovou-se que não há toxicidade aguda; no entanto, há diminuição de biomassa e comprometimento na reprodução quando as minhocas Eisenia fetida são submetidas ao LED in natura e em várias diluições com solo. ${ }^{23}$

\section{Capacidade de troca catiônica (CTC)}

Os resultados obtidos para a CTC estão apresentados na Tabela 2.

Tabela 2. Variação da CTC efetiva durante a vermicompostagem $\left(\mathrm{em} \mathrm{cmol}_{\mathrm{c}} \mathrm{kg}^{-1}\right)$

\begin{tabular}{ccccccccc}
\hline Coletas & $\mathrm{A}$ & $\mathrm{e}$ & $\mathrm{B}$ & $\mathrm{e}$ & $\mathrm{C}$ & $\mathrm{e}$ & Solo & $\mathrm{e}$ \\
\hline $1^{\mathrm{a}}$ & 24,54 & 0,54 & 10,21 & 0,64 & 7,55 & 0,39 & 2,66 & 0,37 \\
$2^{\mathrm{a}}$ & 16,91 & 0,15 & 5,75 & 0,40 & 4,90 & 0,25 & & \\
$3^{\mathrm{a}}$ & 21,97 & 0,39 & 10,38 & 0,29 & 6,35 & 0,39 & & \\
$4^{\mathrm{a}}$ & 17,76 & 0,26 & 8,83 & 0,40 & 5,92 & 0,44 & & \\
$5^{\mathrm{a}}$ & 16,13 & 0,15 & 8,67 & 0,40 & 5,15 & 0,25 & & \\
$6^{\mathrm{a}}$ & 14,85 & 0,29 & 7,55 & 0,39 & 4,63 & 0,26 & & \\
$7^{\mathrm{a}}$ & 17,07 & 0,40 & 7,03 & 0,39 & 4,55 & 0,40 & & \\
\hline
\end{tabular}

$\mathrm{A}=$ Vermicomposto com matriz de $100 \%$ lodo de esgoto doméstico; $\mathrm{B}=$ Vermicomposto com matriz $75 \%$ lodo de esgoto doméstico e $25 \%$ solo; $\mathrm{C}=$ Vermicomposto com matriz $50 \%$ lodo de esgoto doméstico e $50 \%$ solo; $\mathrm{e}=$ erro da medida para $\mathrm{n}=5$, onde $\mathrm{n}=$ número de amostras

Pode-se observar pela Tabela 2 que a CTC apresentou uma tendência à diminuição ao longo do processo de vermicompostagem, $\mathrm{e}$ a exemplo do $\mathrm{pH}$, na $2^{\mathrm{a}}$ coleta apresentou uma redução abrupta; isso faz sentido, uma vez que a CTC depende da acidez do meio. Logo, uma diminuição nos valores de $\mathrm{pH}$ leva, consequentemente, a uma diminuição na CTC.

Apesar de se verificar uma tendência na diminuição em seu valor, a CTC do vermicomposto $\mathrm{C}$, a menor quando comparada com a CTC dos outros vermicompostos ao fim do processo, foi $42 \%$ maior do que a CTC do solo, o que é considerado muito bom em termos de produtividade agrícola. ${ }^{7}$

\section{Carbono orgânico total (COT)}

A Figura 2 apresenta a variação na porcentagem de carbono orgânico total durante os 90 dias de vermicompostagem.

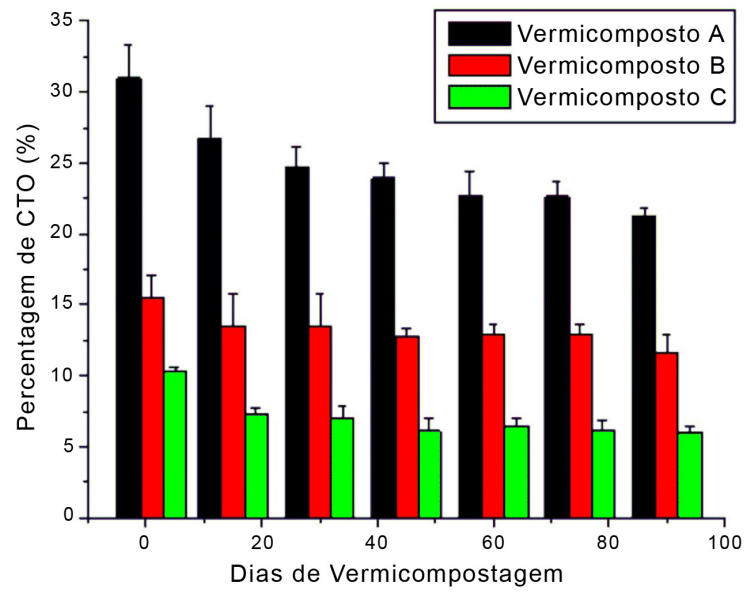

Figura 2. Variação na porcentagem de carbono orgânico total durante os 90 dias de vermicompostagem 
O COT diminui porque durante o processo de vermicompostagem as minhocas utilizam parte do carbono para seu crescimento, ou seja, elas fixam parte do carbono em sua biomassa; outra parte é transformada em $\mathrm{CO}_{2}$ e perdida para o meio externo; finalmente, há formação de um material mais estabilizado.

Como se esperava, com a diminuição da matéria orgânica e do COT, pode-se dizer que houve mineralização, processo que é causado não somente pela alimentação das minhocas, mas que é realizado em ação conjunta destas com os micro-organismos existentes na matriz.

\section{Nitrogênio Kjeldahl total e fósforo}

Nas Tabelas 3 e 4 estão apresentadas a variação na quantidade de NKT durante os 90 dias de vermicompostagem, que corresponde à somatória do conteúdo de nitrogênio orgânico e amoniacal, e a quantidade de fósforo total no início e no final do processo, respectivamente.

Tabela 3. Variação do nitrogênio Kjeldahl total (NKT) em (\%) em massa

\begin{tabular}{ccccccccc}
\hline Coletas & $\mathrm{A}$ & $\mathrm{e}$ & $\mathrm{B}$ & $\mathrm{e}$ & $\mathrm{C}$ & $\mathrm{e}$ & Solo & $\mathrm{e}$ \\
\hline $1^{\mathrm{a}}$ & 2,44 & 0,03 & 1,31 & 0,04 & 0,82 & 0,06 & 0,64 & 0,03 \\
$2^{\mathrm{a}}$ & 2,63 & 0,07 & 1,42 & 0,03 & 0,88 & 0,04 & & \\
$3^{\mathrm{a}}$ & 2,72 & 0,08 & 1,51 & 0,02 & 0,91 & 0,04 & & \\
$4^{\mathrm{a}}$ & 2,94 & 0,06 & 1,63 & 0,03 & 0,93 & 0,05 & & \\
$5^{\mathrm{a}}$ & 3,14 & 0,11 & 1,74 & 0,04 & 0,95 & 0,09 & & \\
$6^{\mathrm{a}}$ & 3,26 & 0,04 & 1,82 & 0,06 & 0,98 & 0,05 & & \\
$7^{\mathrm{a}}$ & 3,37 & 0,04 & 1,86 & 0,04 & 1,01 & 0,09 & &
\end{tabular}

$\mathrm{A}=$ Vermicomposto com matriz de $100 \%$ lodo de esgoto doméstico; $\mathrm{B}=$ Vermicomposto com matriz $75 \%$ lodo de esgoto doméstico e $25 \%$ solo; $\mathrm{C}=$ Vermicomposto com matriz $50 \%$ lodo de esgoto doméstico e $50 \%$ solo; $\mathrm{e}=$ erro da medida para $\mathrm{n}=5$, onde $\mathrm{n}=$ número de amostras

Tabela 4. Variação da quantidade de fósforo nas amostras no início e no final do processo de vermicompostagem, em (\%) em massa

\begin{tabular}{ccccccccc}
\hline Coletas & $\mathrm{A}$ & $\mathrm{e}$ & $\mathrm{B}$ & $\mathrm{e}$ & $\mathrm{C}$ & $\mathrm{e}$ & Solo & $\mathrm{e}$ \\
\hline $1^{\text {a }}$ & 1,12 & 0,09 & 0,85 & 0,19 & 0,71 & 0,16 & 0,48 & 0,09 \\
$7^{\mathrm{a}}$ & 1,18 & 0,07 & 0,88 & 0,17 & 0,79 & 0,11 & & \\
\hline
\end{tabular}

$\mathrm{A}=$ Vermicomposto com matriz de $100 \%$ lodo de esgoto doméstico; $\mathrm{B}=$ Vermicomposto com matriz $75 \%$ lodo de esgoto doméstico e $25 \%$ solo; $\mathrm{C}=$ Vermicomposto com matriz $50 \%$ lodo de esgoto doméstico e $50 \%$ solo; $\mathrm{e}=$ erro da medida para $\mathrm{n}=5$, onde $\mathrm{n}=$ número de amostras

Como se pode observar, as quantidades de NKT aumentaram durante o processo de vermicompostagem, sendo todas maiores do que as encontradas no solo in natura. Isso ocorre, pois, durante o processo de mineralização e respiração, tanto dos micro-organismos quanto das minhocas, a matéria orgânica evolui, em parte, para $\mathrm{CO}_{2}$, havendo desta maneira uma concentração dos macro e micro nutrientes, no caso específico relatado do NKT.

No caso das quantidades de fósforo não houve variação significativa durante o processo. $\mathrm{O}$ aumento de NKT intensifica a capacidade fertilizante do vermicomposto, uma vez que nitrogênio é um dos nutrientes essenciais para o crescimento e desenvolvimento das plantas. Segundo Atiyeh, ${ }^{24} \mathrm{O}$ aumento de nutrientes, tais como nitrogênio, está diretamente relacionado com a mineralização da matéria orgânica pelas minhocas.

\section{Razão C/N}

A razão $\mathrm{C} / \mathrm{N}$ é um indicativo do grau de maturação dos vermicom- postos, sendo aplicada aos fertilizantes orgânicos mistos, compostos e vermicompostos. ${ }^{25}$ Os valores para a variação da razão $\mathrm{C} / \mathrm{N}$ durante o processo de vermicompostagem estão apresentados na Tabela 5.

Tabela 5. Variação da razão $\mathrm{C} / \mathrm{N}$ durante o processo de vermicompostagem

\begin{tabular}{ccccccccc}
\hline Coletas & A & e & B & e & C & e & Solo & e \\
\hline $1^{\mathrm{a}}$ & 16,69 & 1,21 & 13,74 & 1,48 & 14,7 & 1,49 & 2,83 & 0,08 \\
$2^{\mathrm{a}}$ & 11,46 & 0,65 & 11,10 & 1,36 & 9,62 & 0,69 & & \\
$3^{\mathrm{a}}$ & 10,69 & 1,41 & 9,62 & 1,50 & 9,01 & 1,03 & & \\
$4^{\mathrm{a}}$ & 9,51 & 0,40 & 10,15 & 0,68 & 7,60 & 0,72 & & \\
$5^{\mathrm{a}}$ & 8,25 & 0,55 & 8,37 & 0,34 & 7,95 & 0,99 & & \\
$6^{\mathrm{a}}$ & 8,26 & 0,48 & 8,51 & 0,88 & 7,36 & 0,82 & & \\
$7^{\mathrm{a}}$ & 7,64 & 0,35 & 7,23 & 0,88 & 6,96 & 0,58 & & \\
\hline A & & & & & & \\
\hline
\end{tabular}

A = Vermicomposto com matriz de $100 \%$ lodo de esgoto doméstico; $\mathrm{B}=$ Vermicomposto com matriz $75 \%$ lodo de esgoto doméstico e $25 \%$ solo; $\mathrm{C}=$ Vermicomposto com matriz $50 \%$ lodo de esgoto doméstico e $50 \%$ solo; $\mathrm{e}=$ erro da medida para $\mathrm{n}=5$, onde $\mathrm{n}=$ número de amostras

Os valores para a razão $\mathrm{C} / \mathrm{N}$ apresentaram um decréscimo ao longo do processo, de aproximadamente 50\%, e isto ocorre devido à diminuição que se observou na percentagem de COT e ao aumento na quantidade de NKT. A aceleração no processo de humificação, promovido pelas minhocas durante a vermicompostagem, promove uma diminuição na razão $\mathrm{C} / \mathrm{N} .^{24}$

\section{Razão CTC/COT}

A relação CTC/COT é um indicativo do grau de maturação e qualidade dos fertilizantes orgânicos e é considerada como mais apropriada que a relação $\mathrm{C} / \mathrm{N}$ para indicar o grau de humificação de materiais orgânicos, pois esta última pode ser afetada seriamente pela presença de nitrogênio amoniacal, como ocorre no esterco de galinha.

Todos os diferentes parâmetros de caracterização de vermicomposto estão correlacionados em maior ou menor grau, pois refletem basicamente o mesmo processo de reações de estabilização de compostos orgânicos. A vantagem da utilização da capacidade de troca de cátions é que, além de qualificar o material orgânico, esse índice traz uma informação muito significativa do ponto de vista agronômico, ou seja, a melhoria de retenção de nutrientes que esses produtos podem proporcionar ao serem incorporados ao solo. ${ }^{28}$

Os resultados obtidos para razão CTC/COT estão apresentados na Tabela 6.

Tabela 6. Variação da razão CTC/COT durante o processo de vermicompostagem $(\mathrm{c} \mathrm{mol} \mathrm{kg-1})$

\begin{tabular}{ccccccccc}
\hline Coletas & A & e & B & e & C & e & Solo & e \\
\hline $1^{\text {a }}$ & 94,99 & 1,26 & 79,04 & 2,02 & 87,88 & 3,11 & 66,62 & 10,26 \\
$2^{\text {a }}$ & 75,86 & 3,50 & 51,22 & 3,91 & 80,99 & 2,12 & & \\
$3^{\text {a }}$ & 106,69 & 0,79 & 92,40 & 3,65 & 108,39 & 2,03 & & \\
$4^{\text {a }}$ & 88,95 & 2,53 & 82,72 & 3,62 & 117,23 & 3,04 & & \\
$5^{\text {a }}$ & 85,42 & 3,64 & 80,59 & 3,54 & 95,52 & 2,12 & & \\
$6^{\text {a }}$ & 78,68 & 4,59 & 70,34 & 2,69 & 89,90 & 4,17 & & \\
$7^{\text {a }}$ & 96,08 & 2,87 & 72,98 & 2,54 & 90,55 & 3,18 & & \\
\hline
\end{tabular}

$\mathrm{A}=$ Vermicomposto com matriz de $100 \%$ lodo de esgoto doméstico; $\mathrm{B}=$ Vermicomposto com matriz $75 \%$ lodo de esgoto doméstico e $25 \%$ solo; $\mathrm{C}=$ Vermicomposto com matriz $50 \%$ lodo de esgoto doméstico e $50 \%$ solo; $\mathrm{e}=$ erro da medida para $\mathrm{n}=5$, onde $\mathrm{n}=$ número de amostras 
Tabela 7. Quantidade extraída e quantidade extraída em relação ao teor de matéria orgânica, de AH e AF no início (1ª coleta) e no final do processo de vermicompostagem ( $7^{\mathrm{a}}$ coleta)

\begin{tabular}{|c|c|c|c|c|c|c|}
\hline Amostra & QE* AH (\%) & $\mathrm{Q} / \mathrm{MO} * * \mathrm{AH}(\%)$ & $\mathrm{QE}^{*} \mathrm{AF}(\%)$ & $\mathrm{Q} / \mathrm{MO} * * \mathrm{AF}(\%)$ & $\mathrm{QE}^{*} \sum(\mathrm{AH}+\mathrm{AF})(\%)$ & $\mathrm{Q} / \mathrm{MO}^{* *} \sum(\mathrm{AH}+\mathrm{AF})$ \\
\hline $1^{\mathrm{a}}$ Coleta A & $2,37 \pm 0,19$ & $4,15 \pm 0,33$ & $0,75 \pm 0,03$ & $1,31 \pm 0,05$ & $3,12 \pm 0,22$ & $5,46 \pm 0,38$ \\
\hline $7^{\text {a }}$ Coleta A & $1,16 \pm 0,10$ & $2,41 \pm 0,21$ & $0,21 \pm 0,02$ & $0,44 \pm 0,04$ & $1,37 \pm 0,12$ & $2,85 \pm 0,25$ \\
\hline $1^{\text {a Coleta B }}$ & $1,82 \pm 0,17$ & $4,71 \pm 0,44$ & $0,47 \pm 0,06$ & $1,22 \pm 0,16$ & $2,29 \pm 0,23$ & $5,93 \pm 0,60$ \\
\hline $7^{\text {a }}$ Coleta B & $2,96 \pm 0,08$ & $9,83 \pm 0,20$ & $0,13 \pm 0,02$ & $0,44 \pm 0,07$ & $3,09 \pm 0,10$ & $10,27 \pm 0,27$ \\
\hline $1^{\text {a Coleta } C}$ & $2,19 \pm 0,17$ & $8,34 \pm 0,65$ & $0,65 \pm 0,04$ & $2,48 \pm 0,15$ & $2,84 \pm 0,21$ & $10,82 \pm 0,80$ \\
\hline $7^{\text {a }}$ Coleta $\mathrm{C}$ & $3,19 \pm 0,15$ & $15,40 \pm 0,72$ & $0,23 \pm 0,02$ & $1,11 \pm 0,10$ & $3,42 \pm 0,17$ & $16,51 \pm 0,82$ \\
\hline
\end{tabular}

Como a relação CTC/COT leva em consideração a quantidade de COT onde existem interações que promovem existência da CTC, essa relação é considerada como um índice indicativo do grau de humificação do material estudado, pois um aumento nessa relação implica em uma maior quantidade de COT participando das interações com cátions do meio. ${ }^{29}$ Observa-se na Tabela 6 que os valores encontrados apresentam variações aleatórias, pois, apesar da quantidade de COT diminuir ao longo dos 90 dias de experimento, tem lugar a humificação, ou seja, ocorrência de 2 processos antagônicos e simultâneos: mineralização e humificação. Observa-se que os valores encontrados para a razão CTC/ COT no início e ao final são estatisticamente iguais.

\section{Quantificação dos ácidos húmicos e fúlvicos}

A Tabela 7 apresenta as quantidades de ácidos húmicos (AH) e ácidos fúlvicos $(\mathrm{AF})$ dos diferentes vermicompostos, referentes ao primeiro dia ( $1^{\text {a }}$ coleta $)$ e $90^{\circ}$ dia ( $7^{\text {a }}$ coleta $)$.

A quantidade de ácidos húmicos e ácidos fúlvicos extraídos do vermicomposto $\mathrm{C}$ é muito maior que a quantidade extraída dos outros vermicompostos estudados, tanto no início quanto no final do processo de vermicompostagem. Normalizando-se pelo teor de matéria orgânica existente nos respectivos vermicompostos, a quantidade de $\mathrm{AH}$ e AF extraídos, o vermicomposto $\mathrm{C}$ continua a apresentar a maior quantidade de $\mathrm{AH}$ e $\mathrm{AF}$.

Durante o processo de vermicompostagem, observa-se que para os vermicompostos $\mathrm{B}$ e $\mathrm{C}$ a quantidade de $\mathrm{AH}$ aumenta com tempo de vermicompostagem. $\mathrm{O}$ vermicomposto $\mathrm{A}$ apresentou uma significativa diminuição na quantidade de AH. Uma das explicações para tal fato poderia ser a imensa quantidade de micro-organismos presentes no LED puro, que podem ter degradado parte dos $\mathrm{AH}$ presentes no mesmo. Cabe salientar que essa foi a matriz onde houve a menor adaptação das minhocas. A quantidade de micro-organismos diminuiu significativamente quando se acrescentou solo ao lodo. $\mathrm{O}$ ambiente diferente promove a diminuição na quantidade de micro-organismos e, por este motivo, os demais vermicompostos não teriam sofrido degradação dos AH.

Para os AF, observa-se que decrescem com o processo de vermicompostagem, o que é esperado uma vez que os AF são moléculas menores, mais oxigenadas e com maior potencial a degradação. Além disso, acredita-se que os AF "se fundam" formando os AH. O vermicomposto que apresentou a maior quantidade de $\mathrm{AF}$ ao final do processo, como pode ser observado pela Tabela 7 , foi o vermicomposto C.

Messias encontrou para AH extraídos de vermicomposto obtido de esterco bovino, ${ }^{29}$ uma Q/MO AH de $12,75 \%$. Entretanto, os resultados aqui relatados para $\mathrm{AH}$ do vermicomposto $\mathrm{C}$ apresentam uma $\mathrm{Q} /$ MO AH de 15,40\%, o que é excelente do ponto de vista agronômico. Assim, pode-se dizer que a vermicompostagem dos resíduos de uma ETE tem potencial agronômico, agregando valor ao resíduo.

\section{Ovos viáveis de helmintos}

A Tabela 8 apresenta a variação na concentração de ovos viáveis de helmintos ao longo do processo de vermicompostagem.

Tabela 8. Variação na concentração de ovos viáveis de helmintos (resultados expressos em base seca)

\begin{tabular}{cccc}
\hline Coletas & A Ovos* & B Ovos* & C Ovos* \\
\hline $1^{\mathrm{a}}$ & 10,00 & 4,00 & 3,00 \\
$2^{\mathrm{a}}$ & 8,00 & 3,00 & 1,00 \\
$3^{\mathrm{a}}$ & $<0,25$ & $<0,25$ & $<0,25$ \\
$4^{\mathrm{a}}$ & $<0,25$ & $<0,25$ & $<0,25$ \\
$5^{\mathrm{a}}$ & $<0,25$ & 1,00 & $<0,25$ \\
$6^{\mathrm{a}}$ & $<0,25$ & $<0,25$ & $<0,25$ \\
$7^{\mathrm{a}}$ & $<0,25$ & $<0,25$ & $<0,25$ \\
\hline
\end{tabular}

$\mathrm{A}=$ Vermicomposto com matriz de $100 \%$ lodo de esgoto doméstico; $\mathrm{B}=$ Vermicomposto com matriz $75 \%$ lodo de esgoto doméstico e $25 \%$ solo; $\mathrm{C}=$ Vermicomposto com matriz 50\% lodo de esgoto doméstico e 50\% solo; *4 g de amostra seca

A concentração de ovos viáveis de helmintos é reduzida durante o processo de vermicompostagem. Esse fato deve-se, provavelmente, ao processo de alimentação das minhocas. A minhoca se alimenta de matéria orgânica em decomposição e, durante sua alimentação, ingere o solo (no caso o lodo de esgoto e as misturas B e C). Nesse processo de alimentação ela acaba ingerindo também os micro-organismos e os ovos de helmintos presentes no substrato em questão. Ao passar pelo trato digestivo estes micro-organismos acabam morrendo e parte dos ovos viáveis de helmintos são degradados também. Esta seria uma das causas para a diminuição na concentração de ovos viáveis de helmintos. Estudos prosseguem para avaliar o destino dos ovos viáveis de helmintos após o processo de vermicompostagem no organismo das minhocas.

\section{CONCLUSÕES}

Foi demonstrado neste trabalho que o lodo de esgoto doméstico pode ser utilizado como matriz para a produção de vermicomposto, gerando um produto final com razões $\mathrm{C} / \mathrm{N}$ e CTC/COT favoráveis e altos teores de nitrogênio Kjeldahl total.

De maneira geral, a vermicompostagem mostrou-se eficiente para ser utilizada como técnica de estabilização do lodo de esgoto doméstico, sendo que a avaliação do comportamento de algumas variáveis e a relação entre elas indicaram um aumento da humificação da matéria orgânica como, por exemplo, a razão $\mathrm{C} / \mathrm{N}$; além disso, o 
substrato final do tratamento possui um alto potencial para ser utilizado na agricultura como fertilizante orgânico e condicionador de solo.

\section{AGRADECIMENTOS}

Este trabalho foi financiado pela FAPESP, processos número 05/56328-8 e número 07/50776-4, e CNPq. P. R. Dores-Silva agradece ao programa Ensinar com Pesquisa da Universidade de São Paulo, pela bolsa concedida e à Estação de Tratamento de Esgoto de Água Vermelha, pelas amostras.

\section{REFERÊNCIAS}

1. Andreoli, C. V.; Resíduos Sólidos no Saneamento, Processos de Reciclagem e Disposição Final, 1ª ed., Editora Rima: Rio de Janeiro, 2001.

2. USEPA; Biosolids Generation Use and Disposal in the United States, Enviromental Protection Agency, Municipal and Industrial Solid Waste Division, Office of Solid Waste, 1999, p. 75.

3. Fernandes, F.; Andraus, S.; Andreoli, C. V.; Bonnet, B. R. P.; Borges, J. C.; Canto, L. A.; Medeiros, M. L. B.; Sanare 1996, 5, 46.

4. Zeitouni, R. F.; Dissertação de Mestrado, Instituto Agronômico de Campinas, Brasil, 2005.

5. Pires, M. M. A.; Uso Agrícola do Lodo de Esgoto: Aspectos Legais, Embrapa Meio Ambiente: Jaguariúna, 2006.

6. Tsutiya, M. T. Em Biossólidos na Agricultura; Tsutiya, M. T.; Comparini, J. B.; Alem Sobrinho, P.; Hespanhol, I.; Carvalho, P. C. T.; Melfi, A. J.; Melo, W. J.; Marques, M. O., eds.; SABESP: São Paulo, 2001, cap. 4

7. Charles, C.; Sottomaior, A. R.; Andreoli, C. A.; R. Bras. Ci. Solo 2005, 29, 987.

8. Edwards, C. A.; Fletcher, K. E.; Agric. Ecosyst. Environ. 1988, 24, 235.

9. Aquino, A. M.; Almeida, D. L.; Silva, V. F.: Comunicado Técnico, 8, Centro Nacional de Pesquisa Biológica do Solo: Rio de Janeiro, 1992.

10. Yadav, A.; Garg, V. K.; J. Hazard. Mater. 2009, 168, 262.

11. Sinha, R. K.; Heart, S.; Bharambe, G.; Brahambhatt, A.; Waste Manag. Res. 2010, 28, 872.
12. Motter, O. F.; Kiehl, E. J.; Kawai, H.; Medel, L. E.; Yoshimoto, H.; Utilização de Minhocas na Produção de Composto Orgânico, CETESB: São Paulo, 1990.

13. Raut, M. P.; Prince-William, S. P. M.; Bhattacharyya, J. K.; Chakrabarti, T.; Devotta S.; Bioresour. Technol. 2008, 99, 6512.

14. Aalok, A.; Tripathi, A. K.; Soni, P.; J. Hum. Ecol. 2008, 24, 59.

15. Garg, P.; Gupta, A.; Saty, S.; Bioresour. Technol. 2006, 97, 391.

16. Tsutiya, M. T. Em Impacto Ambiental do Uso Agrícola do Lodo de Esgoto; Bettiol, W.; Camargo, O. A., eds.; Embrapa Meio Ambiente: Jaguariúna, 2000. cap. 4.

17. Bettiol, W.; Camargo, O. A.; Embrapa Meio Ambiente: Jaguariúna, 2000.

18. Kiehl, E. J.; Fertilizantes Orgânicos, Agronômica Ceres Ltda.: Piracicaba, 1985.

19. Cotta, J. A. O.; Salami, F. H.; Marques, A. R.; Rezende, M. O. O.; Landgraf, M. D.; Revista Analytica 2007, 26, 68.

20. Soccol, V. T.; Paulino, R. C.; Castro E. A.; Metodologia de Análise Parasitológica em Lodo de Esgoto e Esgoto, SANEPAR/PROSAB: Paraná, 1998.

21. http://www.ihss.gatech.edu/soilhafa.html, acessada em Janeiro 2008.

22. Albertini, L. B. A.; Silva, L. C.; Rezende, M. O. O.; Tratamento de Resíduos Químicos: Guia Prático para a Solução dos Resíduos Químicos em Instituições de Ensino Superior, $1^{\mathrm{a}}$ ed., Editora Rima: São Carlos, 2005.

23. Dores-Silva, P. R.; Landgraf, M. D.; Rezende, M. O. O.; J. Braz. Soc. Ecotoxicol, no prelo.

24. Atiyeh, R. M. S.; Lee, C. A.; Edwards, N. Q.; Metzger, J. D.; Bioresour. Technol. 2002, 84, 7 .

25. http://www.agricultura.gov.br, acessada em Fevereiro 2010 e Março 2011.

26. Kayhanian, M.; Tchobanoglous, G.; Water Sci. Technol. 1993, 27,133.

27. Rodella, A. A.; Tese de Livre Docência, Universidade de São Paulo, Brasil, 1996.

28. Roig, A.; Lax, A.; Cegarra, J.; Costa, F.; Jernadez, M. T.; Soil Sci. 1988, 146, 311.

29. Messias, R. A.; Tese de Doutorado, Universidade de São Paulo, Brasil, 2004. 